\title{
Fabrication of Efficient Low-Bandgap Perovskite Solar Cells by Combining Formamidinium Tin lodide with Methylammonium Lead lodide
}

Weiqiang Liao, ${ }^{\dagger,}, \#$ Dewei Zhao, ${ }^{*} \dagger,{ }^{\dagger}$ Yue Yu,${ }^{\dagger}$ Niraj Shrestha,${ }^{\dagger}$ Kiran Ghimire, ${ }^{\dagger}$ Corey R. Grice, ${ }^{\dagger}$ Changlei Wang, ${ }^{\dagger},{ }^{\top}$ Yuqing Xiao, ${ }^{\pi}$ Alexander J. Cimaroli, ${ }^{\dagger}$ Randy J. Ellingson, ${ }^{\dagger}$ Nikolas J. Podraza, ${ }^{\dagger}$ Kai Zhu, ${ }^{\S}$ Ren-Gen Xiong, ${ }^{*}, \vec{\uparrow}$ and Yanfa Yan ${ }^{*}, \dagger$

${ }^{\dagger}$ Department of Physics and Astronomy and Wright Center for Photovoltaics Innovation and Commercialization, The University of Toledo, Toledo, Ohio 43606, United States.

*Ordered Matter Science Research Center, Southeast University, Nanjing 211189, P. R. China.

"Key Laboratory of Artificial Micro/Nano Structures of Ministry of Education, School of Physics and Technology, Wuhan University, Wuhan, 430072, China

${ }^{\S}$ Chemistry and Nanoscience Center, National Renewable Energy Laboratory, Golden, Colorado 80401, United States

\section{Corresponding Authors}

dewei.zhao@utoledo.edu

xiongrg@seu.edu.cn

yanfa.yan@utoledo.edu

\section{Author Contributions}

${ }^{\#}$ W.L. and D.Z. contributed equally to this work. 


\section{Experimental Section}

\section{Film preparation:}

The $\mathrm{FASnI}_{3}$ precursor solution was prepared by dissolving $372 \mathrm{mg}$ of $\mathrm{SnI}_{2}$ (Sigma-Aldrich) and $172 \mathrm{mg}$ of formamidinium iodide (FAI) (Dyesol) with $10 \mathrm{~mol} \%\left(15.6 \mathrm{mg}\right.$ ) of $\mathrm{SnF}_{2}$ in 800 $\mu \mathrm{L}$ N,N-dimethylmethanamide (DMF) (anhydrous, Sigma-Aldrich) and $200 \mu \mathrm{L}$ dimethyl sulfoxide (DMSO) (anhydrous, Sigma-Aldrich). The $\mathrm{MAPbI}_{3}$ precursor solution was prepared by dissolving $461 \mathrm{mg} \mathrm{PbI}_{2}$ (Sigma-Aldrich) and $159 \mathrm{mg} \mathrm{CH} \mathrm{NH}_{3} \mathrm{I}$ (Dyesol) with $3.5 \mathrm{~mol} \%$ $(11.3 \mathrm{mg}) \mathrm{Pb}(\mathrm{SCN})_{2}$ (Sigma-Aldrich) dissolved in $630 \mu \mathrm{L}$ DMF and $70 \mu \mathrm{L}$ DMSO. The $\left(\mathrm{FASnI}_{3}\right)_{1-\mathrm{x}}\left(\mathrm{MAPbI}_{3}\right)_{\mathrm{x}}(\mathrm{x}=0.0,0.2,0.4,0.6,0.9$, and 1.0) precursor solutions were obtained by mixing stoichiometric amounts of $\mathrm{FASnI}_{3}$ and $\mathrm{MAPbI}_{3}$ perovskite precursors. The mixed solutions are kept for 30 min before spin coating. The $\left(\mathrm{FASnI}_{3}\right)_{1-\mathrm{x}}\left(\mathrm{MAPbI}_{3}\right)_{\mathrm{x}}$ precursors were spin-coated onto ITO/PEDOT:PSS at 5,000 rpm for $60 \mathrm{~s}$. Diethyl ether was dropped onto the spinning substrate during the spin-coating. All perovskite films were annealed at $100{ }^{\circ} \mathrm{C}$ for 5 min in a glove box. The samples for SEM measurement were obtained by spin-coating these precursor solutions onto ITO/PEDOT:PSS. The samples for UV-Vis were prepared by spincoating these precursor solutions onto glass/PEDOT:PSS. The samples for spectroscopic ellipsometry (SE) were deposited onto native oxide coated crystal Si wafers. The samples for TRPL measurement was deposited on bare glass and covered by a $30 \mathrm{~nm}$ thick film of poly(methyl methacrylate) (PMMA).

\section{Device fabrication:}

The pre-patterned ITO substrates were cleaned by ultra-sonication in diluted Micro-90 detergent, deionized water, acetone, and isopropanol for $15 \mathrm{~min}$, respectively. PEDOT:PSS films were coated on the cleaned ITO substrate at $4000 \mathrm{rpm}$ for $50 \mathrm{~s}$ and then dried at $175^{\circ} \mathrm{C}$ for $30 \mathrm{~min}$. The $\left(\mathrm{FASnI}_{3}\right)_{1-\mathrm{x}}\left(\mathrm{MAPbI}_{3}\right)_{\mathrm{x}}(\mathrm{x}=0.0,0.2,0.4,0.6,0.9$, and 1.0) perovskite films were deposited by spin-coating the precursor solution onto PEDOT:PSS film at 5,000 rpm for 
60 s. Diethyl ether was dropped onto the spinning substrate during the spin-coating. All perovskite films were annealed at $100{ }^{\circ} \mathrm{C}$ for $5 \mathrm{~min}$ in a glove box. Finally, $\mathrm{C}_{60}(20 \mathrm{~nm}) / \mathrm{BCP}$ $(5 \mathrm{~nm}) / \mathrm{Ag}(75 \mathrm{~nm})$ were sequentially deposited by thermal evaporation to complete the fabrication. The active area of each device is $0.12 \mathrm{~cm}^{2}$. Devices were encapsulated with cover glass and UV-curable epoxy.

\section{Film and device characterization:}

Perovskite films were imaged with a high resolution field emission scanning electron microscope (SEM) (Hitachi S-4800). The crystal structure of the $\left(\mathrm{FASnI}_{3}\right)_{1-\mathrm{x}}\left(\mathrm{MAPbI}_{3}\right)_{\mathrm{x}}(\mathrm{x}$ $=0.0,0.2,0.4,0.6,0.8,0.9$, and 1.0) films was examined by X-ray diffraction (XRD) (RigakuUltima III) with $\mathrm{Cu} \mathrm{K \alpha}$ radiation under operation conditions of $40 \mathrm{kV}$ and $44 \mathrm{~mA}$. The absorption spectra were measured by UV-Vis spectrophotometer (PerkinElmer Lambda 1050). Complex dielectric function, $\varepsilon=\varepsilon_{1}+i \varepsilon_{2}$, spectra were obtained from analysis of

ellipsometric spectra collected from 0.74 to $5.0 \mathrm{eV}$ (J. A. Woollam Co. M-2000). Ellipsometric spectra were analyzed to determine $\varepsilon$ with a structural model consisting of a perovskite film (variable thickness and surface roughness) on the appropriate underlying substrate. A Kramers-Kronig consistent B-spline model with $0.07 \mathrm{eV}$ node spacings were used to determine layer thicknesses. Thicknesses were fixed and numerical inversion used to extract $\varepsilon$. The absorption onset, reflected in $\varepsilon_{2}$, initially decreases with $\mathrm{x}$, reaches a minimum at $\mathrm{x}=0.4$, then increases. All layer thicknesses were determined using a Dektak surface profiler and calibrated by results from ellipsometry.

For steady-state PL, a $532 \mathrm{~nm} \mathrm{cw}$ laser beam (spot diameter $\approx 90 \mu \mathrm{m}$ ) at $110 \mathrm{~mW} / \mathrm{cm}^{2}$ was used as a source of excitation. The PL signal was detected by a Horiba Symphony-II CCD detector after a $300 \mathrm{~g} / \mathrm{mm}$ grating monochromator (iHR-320). Time-resolved photoluminescence (TRPL) measurements were performed using a time correlated single photon counting (TCSPC) module (Becker \& Hickel Simple Tau SPCM 130-E/M module). A 
$532 \mathrm{~nm}$ pulsed laser (Fianium model SC400-2, $\sim 5$ ps pulsewidth, $\sim 150 \mu \mathrm{m}$ spot diameter) was used as the source of excitation. Radiative recombination events were detected via a hybrid detector (Hamamatsu HPM-100-50) and NIR PMT (Hamamatsu H10330B-75) after dispersion by an iHR-320 monochromator (900 g/mm, $850 \mathrm{~nm}$ blaze) grating. Laser intensities and repetition rates used for TRPL measurements are presented in Table S2.

The mean photogenerated carrier lifetime (see Table S2) is calculated by the weighted average of a double exponential fit as follows, where $\mathrm{W}$ represents the system response function:

$$
\begin{gathered}
y(t)=(W \times f)(t) \\
f(t)=A_{1} \times \mathrm{e}^{\frac{-t}{\tau_{1}}}+A_{2} \times \mathrm{e}^{\frac{-t}{\tau_{2}}}
\end{gathered}
$$

Mean life time $=\langle\tau\rangle=\frac{A_{1} \tau_{1}^{2}+A_{2} \tau_{2}^{2}}{A_{1} \tau_{1}+A_{2} \tau_{2}}$

$J-V$ curves were measured in air under $100 \mathrm{~mW} / \mathrm{cm}^{2}$ AM1.5G solar irradiation (PV Measurements Inc.) with a Keithley 2400 Source Meter. EQE spectra were performed on a QE system (PV Measurements Inc.). All characterizations and measurements were performed in the ambient. 

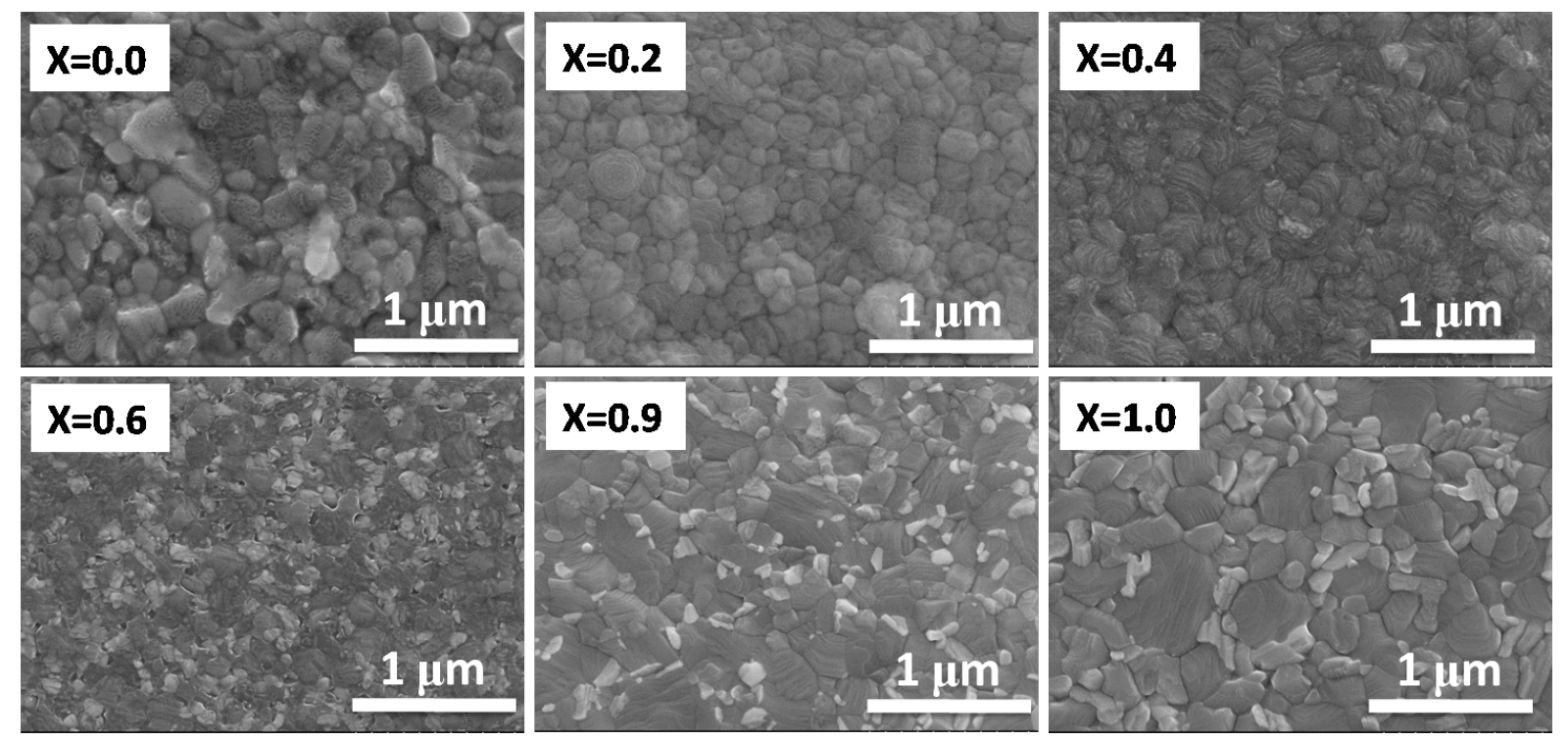

Figure S1. SEM images of $\left(\mathrm{FASnI}_{3}\right)_{1-\mathrm{x}}\left(\mathrm{MAPbI}_{3}\right)_{\mathrm{x}}$ perovskite thin films with $\mathrm{x}=0,0.2,0.4$, $0.6,0.9$, and 1.0 . 
(a) $X=0.0 ; R M S=14.8 \mathrm{~nm}$

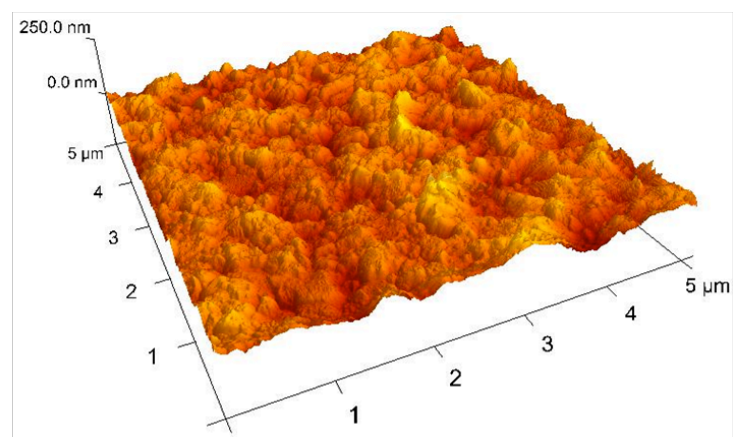

(b) $X=0.4 ; R M S=6.8 \mathrm{~nm}$

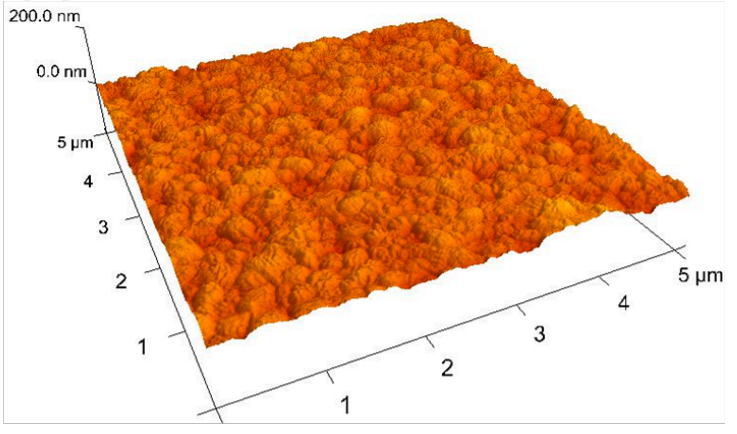

(c) $X=1.0 ; R M S=9.5 \mathrm{~nm}$

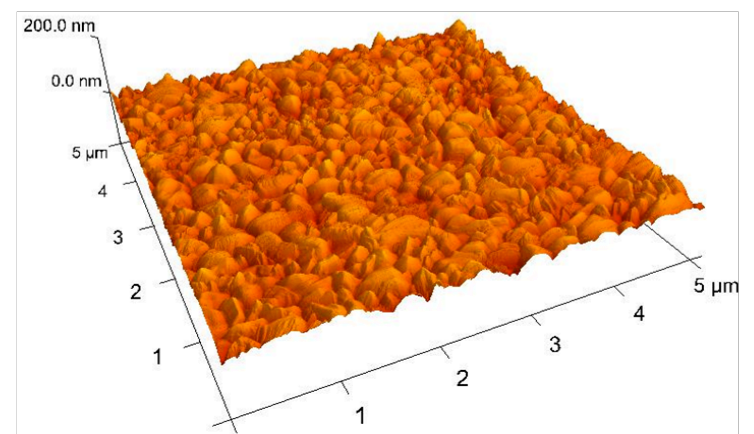

Figure S2. 3D AFM images of $\left(\mathrm{FASnI}_{3}\right)_{1-\mathrm{x}}\left(\mathrm{MAPbI}_{3}\right)_{\mathrm{x}}$ perovskite thin films: (a) $\mathrm{x}=0.0$, RMS $=14.8 \mathrm{~nm}$; (b) $\mathrm{x}=0.4$, RMS $=6.8 \mathrm{~nm}$; and (c) $\mathrm{x}=1.0, \mathrm{RMS}=9.5 \mathrm{~nm}$. 


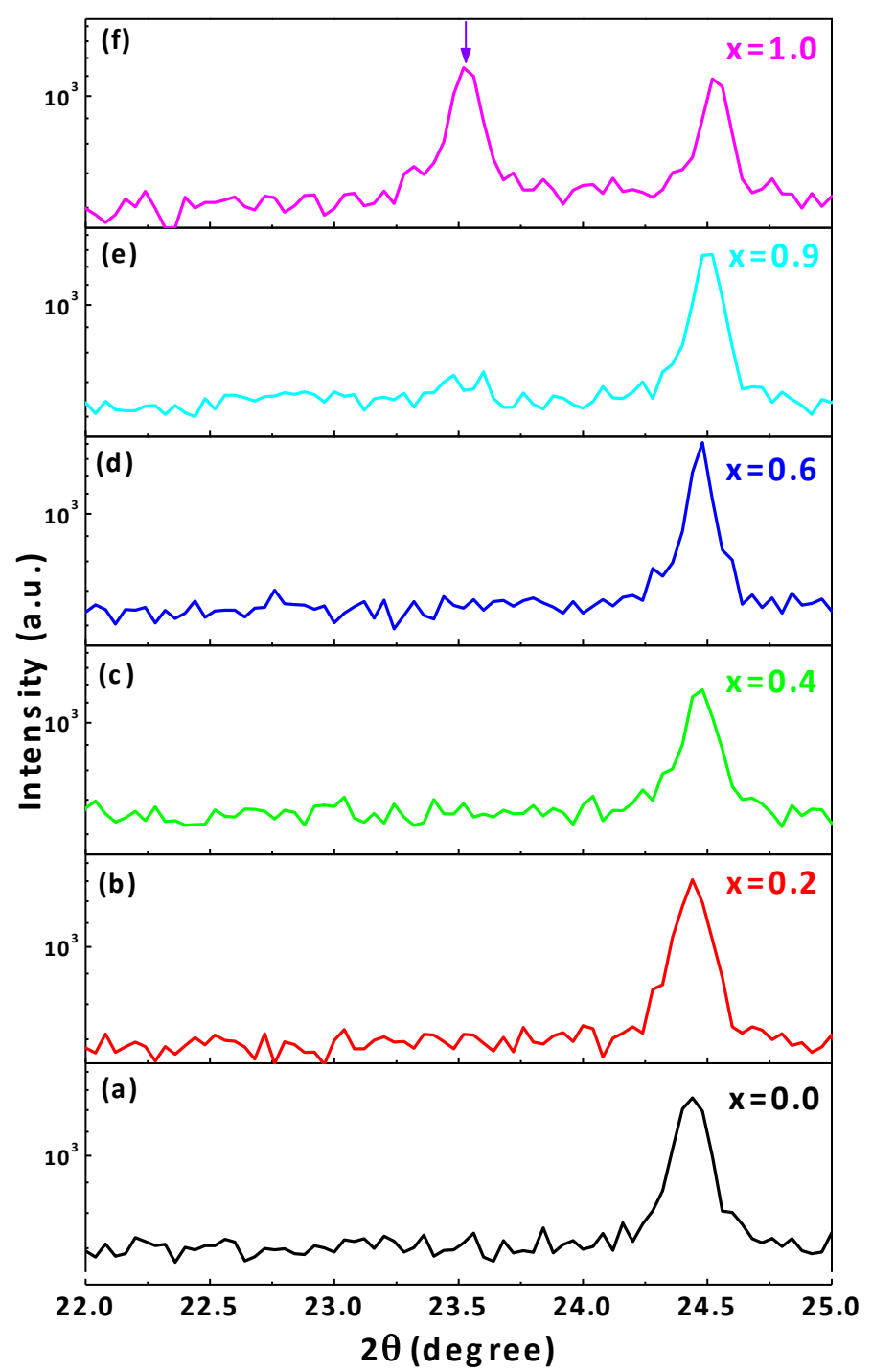

Figure S3. (a) XRD patterns at the range of $22-25^{\circ}$ of $\left(\mathrm{FASnI}_{3}\right)_{1-\mathrm{x}}\left(\mathrm{MAPbI}_{3}\right)_{\mathrm{x}}$ perovskites: (a) $\mathrm{x}=0.0,(\mathrm{~b}) \mathrm{x}=0.2,(\mathrm{c}) \mathrm{x}=0.4,(\mathrm{~d}) \mathrm{x}=0.6,(\mathrm{e}) \mathrm{x}=0.9$, and (f) $\mathrm{x}=1.0$. 

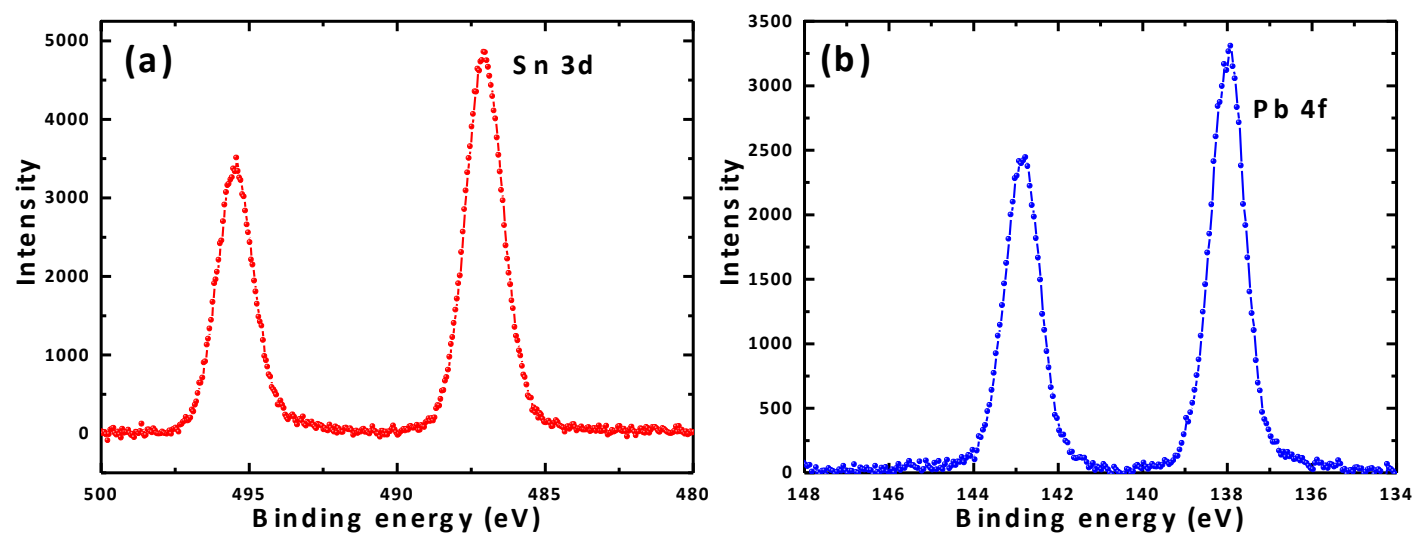

Figure S4. XPS spectra of $\left(\mathrm{FASnI}_{3}\right)_{0.6}\left(\mathrm{MAPbI}_{3}\right)_{0.4}$ perovskite film: (a) Sn 3d bands and (b) $\mathrm{Pb}$ 4f bands. The intensity shows the atomic ratio of $\mathrm{Pb} 4 \mathrm{f}$ to $\mathrm{Sn} 3 \mathrm{~d}$ is $40.73 \%$ : $59.27 \%$. 


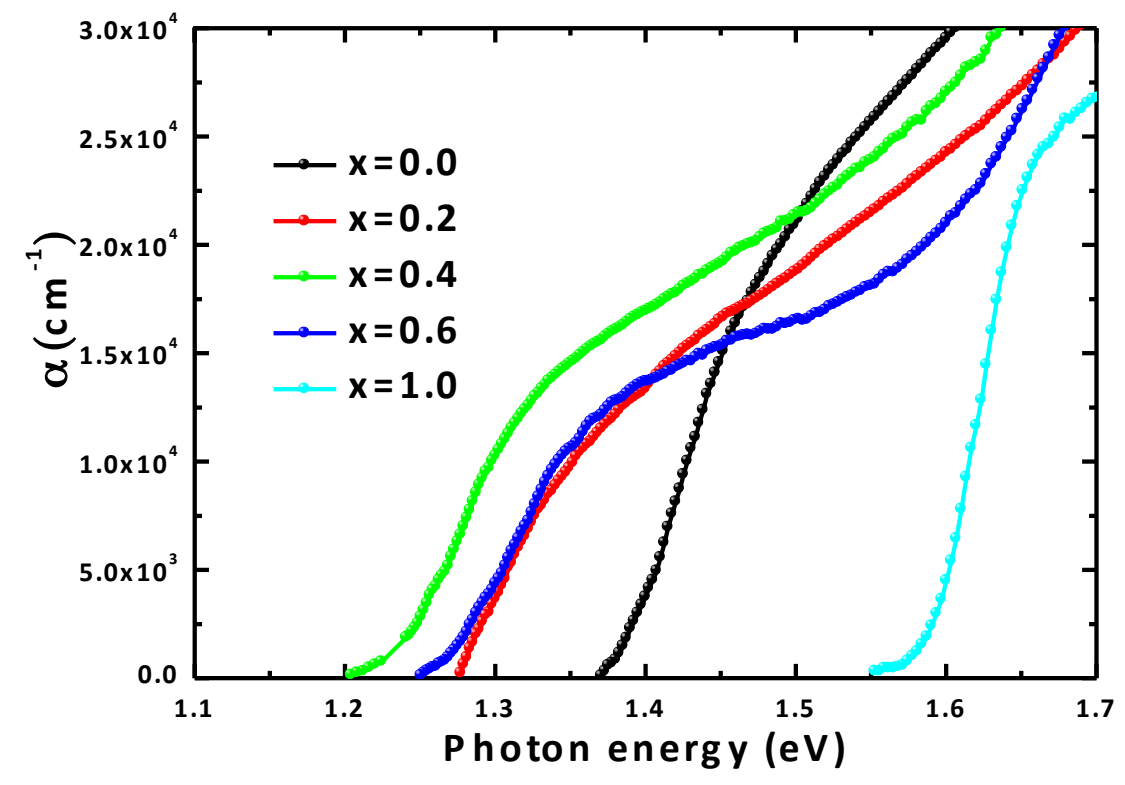

Figure S5. Absorption spectra of $\left(\mathrm{FASnI}_{3}\right)_{1-\mathrm{x}}\left(\mathrm{MAPbI}_{3}\right)_{\mathrm{x}}$ perovskite thin films obtained from SE. The absorption onset initially decreases with $\mathrm{x}$, reaches a minimum at $\mathrm{x}=0.4$, and then increases. 
Table S1. Summary of performance metrics of $\left(\mathrm{FASnI}_{3}\right)_{0.6}\left(\mathrm{MAPbI}_{3}\right)_{0.4} \mathrm{PVSC}$ measured under different scan speed and scan direction.

\begin{tabular}{cccccc}
\hline $\begin{array}{c}\text { Scan speed } \\
(\mathrm{V} / \mathrm{s})\end{array}$ & $\begin{array}{c}\text { Scan } \\
\text { direction }\end{array}$ & $\begin{array}{c}\mathrm{V}_{\text {oc }} \\
(\mathrm{V})\end{array}$ & $\begin{array}{c}\mathrm{J}_{\text {sc }} \\
\left(\mathrm{mA} / \mathrm{cm}^{2}\right)\end{array}$ & $\begin{array}{c}\text { FF } \\
(\%)\end{array}$ & $\begin{array}{c}\text { PCE } \\
(\%)\end{array}$ \\
\hline \multirow{2}{*}{1.00} & R->F & 0.801 & 26.5 & 69.1 & 14.7 \\
& F->R & 0.799 & 26.3 & 68.7 & 14.4 \\
0.20 & R->F & 0.790 & 26.3 & 69.0 & 14.3 \\
& F->R & 0.796 & 26.4 & 67.8 & 14.2 \\
0.10 & R->F & 0.805 & 26.4 & 68.2 & 14.5 \\
& F->R & 0.792 & 26.3 & 69.2 & 14.4 \\
\hline
\end{tabular}

Table S2. Photogenerated carrier lifetime and detection wavelength at different repetition rate and laser intensities. Carrier lifetime is the weighted mean value from a double-exponential fit.

\begin{tabular}{|c|c|c|c|c|}
\hline $\begin{array}{c}\text { Sample } \\
\text { Name }\end{array}$ & $\begin{array}{c}\text { Detection } \\
\text { wavelength } \\
(\mathbf{n m})\end{array}$ & $\begin{array}{c}\text { Average laser } \\
\text { intensity } \\
\left(\mathbf{m W} / \mathbf{c m}^{2}\right)\end{array}$ & $\begin{array}{c}\text { Repetition } \\
\text { rate (MHz) }\end{array}$ & $\begin{array}{c}\text { Carrier } \\
\text { life time } \\
\text { (ns) }\end{array}$ \\
\hline FASnI $_{\mathbf{3}}$ & 886 & 1 & 20 & 0.2 \\
\hline$\left(\mathbf{F A S n I}_{\mathbf{3}} \mathbf{0 . 6}_{\mathbf{0 . 6}}\left(\mathbf{M A P b I}_{\mathbf{3}}\right)_{\mathbf{0 . 4}}\right.$ & 966 & 350 & 5 & 6.7 \\
\hline $\mathbf{M A P b I}_{\mathbf{3}}$ & 775 & 2.6 & 0.5 & 169 \\
\hline
\end{tabular}

